\title{
DIGITAL RECONSTRUCTION OF AN ARCHAEOLOGICAL SITE BASED ON THE INTEGRATION OF 3D DATA AND HISTORICAL SOURCES
}

\author{
G. Guidi ${ }^{\text {a, } *}$, M. Russo ${ }^{\text {b }}$, D. Angheleddu ${ }^{\text {a }}$ \\ ${ }^{a}$ Dept. of Mechanics, Politecnico di Milano, Italy \\ (gabriele.guidi, davide.angheleddu)@polimi.it \\ ${ }^{\mathrm{b}}$ Dept. of Design, Politecnico di Milano, Italy \\ michele.russo@polimi.it
}

Commission V, WG V/4

KEY WORDS: 3D survey, archaeological sites, reality based modeling, digital reconstruction, integration of methods, Cham Architecture

\begin{abstract}
:
The methodology proposed in this paper in based on an integrated approach for creating a 3D digital reconstruction of an archaeological site, using extensively the 3D documentation of the site in its current state, followed by an iterative interaction between archaeologists and digital modelers, leading to a progressive refinement of the reconstructive hypotheses. The starting point of the method is the reality-based model, which, together with ancient drawings and documents, is used for generating the first reconstructive step. Such rough approximation of a possible architectural structure can be annotated through archaeological considerations that has to be confronted with geometrical constraints, producing a reduction of the reconstructive hypotheses to a limited set, each one to be archaeologically evaluated. This refinement loop on the reconstructive choices is iterated until the result become convincing by both points of view, integrating in the best way all the available sources.

The proposed method has been verified on the ruins of five temples in the My Son site, a wide archaeological area located in central Vietnam. The integration of 3D surveyed data and historical documentation has allowed to support a digital reconstruction of not existing architectures, developing their three-dimensional digital models step by step, from rough shapes to highly sophisticate virtual prototypes.
\end{abstract}

\section{INTRUDUCTION}

Reconstructing ancient buildings and cities from their remains has been one of the main applications of computer graphics in Archaeology for its suggestive potential. Behind a generic imaginative effect that might be considered fake or purely spectacular by purists of the archaeological science, in several cases it has been demonstrated that seeing a reconstructed artifact in a realistic simulated context, may allow obtaining new archaeological discoveries. As shown by some authors (Frischer and Dakouri-Hild, 2008), the visualization of actual shapes and their geometrical relationships with the context only explained in verbal form in a traditional approach - may act as a trigger to imagine novel scenarios.

On the other hand, the logical path leading from an archaeological site to a reasonable reconstructive hypothesis is full of pitfalls that can lead to multiple solutions, even very different from each other due to multiple levels of interpretation of the historical sources that can be used for such purpose. The problem, already quite complex when considered in the two dimensions of the buildings footprints, is further complicated when the third dimension of the elevations, generally much less documented in the historical sources, is added.

The many experiments conducted in the past twenty years have been anyway conducted in large majority on available sources and existing surveys rather than facing the problem as a multidisciplinary problem, as it is.

This paper tries to focus which subjects are interrelated in this process, and how a proper integration of them may greatly help in enhancing the reliability of some reconstructive hypotheses, inferring a philological reasoning from purely geometric considerations.

Integrating the usual set of data supplied by historical sources, on which 3D reconstructions are typically based, with the accurate 3D shape detectable with up-to-date passive or active 3D capturing methods, suitable for supplying a good starting point for the reconstruction process, it's a first step not yet exploited enough.

A second point, leading to a potential weakness of the whole reconstructive process, lies in the interaction between the operator technically able to create a 3D model from a CAD system, rendering and presenting it trough CG animations, and the expert of archaeology and architectural grammars, that are often two different persons, often speaking different scientific languages.

Therefore at least three actions, coming from different cultural domains, has to be adequately interleaved for generating a positive cross-fertilization in reconstructing an archaeological artifact:

- assuming that it is still available in some form (modified or simply ruined), a detailed 3D acquisition of the shape and colors of the artifact, leading to its high resolution reality-based digital model. The experts for this jobs are typically engineers and technical staff, working with laser scanners, photogrammetry or computer vision and processing 3D data up to a textured polygonal model or at least a

* Corresponding author. This is useful to know for communication with the appropriate person in cases with more than one author. 
colored cloud of 3D points coherent with the real scenario;

- $\quad$ collecting as much documentation on the artifact as possible, coming from archeological considerations, written historical references, ancient topography, iconographic sources, legends, local uses, religious behaviors and other elements related to the present and past context arrangements. Here the expertise needed is historical, archaeological, artistic, philosophical and generally speaking, humanistic;

- $\quad$ synthesizing both sets of data in a new handmade digital model, first sketching some rough hypotheses, then iteratively refining the reconstructed artifact shape thanks to the feedback given by "humanistic" elements on the one hand, and objective geometrical data given by the reality based model on the other hand. The expertise required is technical as for the first activity, but the background is here more oriented to CAD and Computer Graphics.

A possible weakness in the reconstruction process, observed in past projects, is represented by the possible lack of scientific reliability on the reconstructed model due to the actual disjunction between the modelers producing the final computer graphics output, the archeologist owning the knowledge for creating the appropriate reconstructive hypotheses, and the actual 3D data coming from the detailed survey.

The methodology here proposed suggests some interaction steps for gaining the maximum reliability from the available data, trying to maximize their mutual inference.

The case study used for testing this process was a set of five temples in the UNESCO world heritage site of MySon, a large archaeological area in Vietnam. MySon is a cluster of partially ruined Hindu temples constructed between the 4th and the 14th century $\mathrm{AD}$ by the Champa civilization, living at that time between Vietnam, Cambodia and Laos. MySon is hidden in a circular valley located in the Quảng Nam province of Central Vietnam, $69 \mathrm{~km}$ southwest of Da Nang and $35 \mathrm{~km}$ from the touristic city of Hoi An. The 72 temples in this archaeological site are grouped according to a strict rule. In each group the main temple (Kalan), containing the most secret religious symbols, lies in a square area limited by a wall defining a holy enclosure whose entrance, aligned with the Kalan longitudinal axis, is called Gopura. Along the same line, out of the wall border and in front of the Gopura, a larger building called Mandapa is located. It was conceived as the room for the reception of the monks, before the entrance of a small selected group of priests in the inner part of the Kalan. A small building called Posa, for housing the temple's stela, was also placed out of the holy enclosure. In MySon several similar groups of temples have been found and named with letters from A to $\mathrm{H}$. The G group, on the top of a hill, assigned to an Italian mission for restoration, was the "test object" for the process here described.

The buildings considered have the following numbering:

$\mathrm{G} 1=$ the sanctuary (Kalan)

$\mathrm{G} 2$ = the gateway, miniature copy of the temple (Gopura)

$\mathrm{G} 3=$ the assembly hall (Mandapa)

G4 = the south building (Kosagrha)

$\mathrm{G} 5=$ pavilion for the foundation stone (Posa)

Before the restoration of the complex, an intensive excavation campaign has been carried out in the area, revealing numerous architectural decorations (Hardy et al., 2009). Most of them were $3 \mathrm{D}$ digitised within this project, as the architectural shape of the five buildings described above.

\section{METHODOLOGY}

The process supporting the transformation from a set of 3D point clouds to a polygonal model is well known since more than a decade (Levoy et al., 2000; Bernardini and Rushmeier, 2002; Beraldin et al., 2002), even if in it has been progressively improved to suite better with the field of application. For this reason in the last years many advances have been suggested in order to improve this process in the archaeological field (ElHakim et al., 2008; Guidi et al., 2009; Remondino, 2011).

The reality-based digital model had different purposes in this project, giving: i) an accurate documentation on the whole site, never made before at this level of detail; ii) a reality-based virtual representation of the site for explaining the structure of the $\mathrm{G}$ group to non-expert people like students or common visitors; iii) the starting point for the following modeling phase. The path from reality-based to interpretative models is not so widely developed as the conventional modeling from real data (Russo and Guidi, 2011). In this case, besides the particular attention given to the integration between 3D surveyed data and historical sources, a precise iterative feedback strategy was defined in order to check every important interpretative step during the virtual reconstruction. This procedure was based on a sequence of archaeologist's controls on the modeling evolution, starting from a volumetric simplified version to the best-detailed one. The application of this approach allows to reach a better shared solution between 3D starting data, historical sources and archaeological knowledge, simplifying the communication between historical and technological experts.

Since the starting point is the actual shape of the ruins, the first step of the process was to section the reality-based 3D models with appropriate planar sections. The result is a set of lines with the typical irregularities due to the measurement uncertainty of the active or passive equipment used for capturing the shape of the artifact and some useful geometrical relationships between the architectural elements still available. A suitable technology for this first step might be both photogrammetry or laser scanning. In case of particularly ruined buildings such as some of those in the MySon site, the dense cloud of points generated by a laser scanner was considered more useful than a sparse cloud attainable with a traditional photogrammetric approach.

\section{SURVEY EQUIPMENT AND OPERATIONS}

\subsection{Planning}

As well known several factors may affect the quality of 3D data acquired by a range device. Equipment choices, logistics and environmental conditions, has to be considered in a survey planning, especially when operating in the middle of a forest, like in this specific case. An accurate evaluation of such factors allows optimizing the $3 \mathrm{D}$ acquisition, minimizing possible problems that can occur during the survey. In addition logistics and weather conditions become crucial specially if the survey project has to be planned abroad, with no possibility to travel back and forth to the lab, and little or no possibility to lose operating days for possible logistic delays (such as for example days or weeks lost for custom controls, typical when instrumentation is sent trough a courier), or on the field, due to bad climate conditions

The range sensing technology chosen for this project was Continuous Wave (CW) laser scanning with detection of phase deviation. This is now implemented in several devices from the major manufacturers, including the affordable Focus3D lasers scanner from Faro that was employed in this case. This choice was made because it appears as very suitable for low-middle ranges in terms of tradeoff between precision (around $2 \mathrm{~mm}$ 
standard deviation tested on a planar target located at $20 \mathrm{~m}$ from the instrument), working speed ( 1 million points per second max), equipment weight and size (5 $\mathrm{kg}$ of material fitting in a small bag, compliant with airlines standards for hand-luggage), and, last but not least, a cost definitely lower than other analogous products on the market.

Before starting the project a few considerations have been made about the possibility to use dense image matching as an alternative to laser scanner, being nowadays a powerful tool for generating textured point clouds. The advantage would have been to limit even more the amount of equipment to carry from the lab, consisting in just a camera, a tripod and a PC for checking the data. At the moment of project planning (December 2010) such technologies were very promising but not yet developed as today (February 2013). As a consequence the choice was, as often happens in projects where the site to be digitized is not easily reachable, to get redundant 3D information from multiple sensors. Therefore it was decided to carry to the archaeological site both the equipment needed for laser scanning and dense image processing. Laser scanning was the main tool being metrical, reliable, and already used by the authors in plenty of other projects, while image processing was only experimented on the site with a few datasets. For all these reasons in addition to the above mentioned laser scanner from Faro, a Canon 5D Mark II digital camera was delivered to the excavated area.

Before leaving for the acquisition campaign, the scanner performances were accurately tested in laboratory, verifying the data quality, reliability and ideal working distance. A similar performance test was repeated on the archaeological site, verifying the real behavior of the electronic and optical system with high temperature and extreme humidity condition, using the actual surfaces of the monument as test objects. Different instrument set-ups were then defined, connecting a set of distances with relative 3D scanner performances.

\begin{tabular}{|l|l|l|l|}
\hline \multirow{2}{*}{ Scan Scale } & \multirow{2}{*}{$\begin{array}{c}\text { Operating } \\
\text { Distance (m) }\end{array}$} & \multicolumn{2}{|c|}{ Resolution } \\
\cline { 3 - 4 } & $8-16$ & Qualitative & mm \\
\hline Framework & $8-16$ & Mearse & $7-60$ \\
\hline Architecture & $4-8$ & High & 1 \\
\hline Details & 1 & \multicolumn{2}{|c|}{} \\
\hline
\end{tabular}

Table 1. Laser Scanner Set-up

The archaeological plan was examined in order to suggest a first optimized network of scan positions, trying both to minimize the acquisition time and to consider all the morphological characteristics of the architectural examples.

The 3D survey of the area was planned following three different steps. In the first one all the architectures were acquired, adapting the number of scans and working distance set-up to the different level of geometrical complexity of every single ruin. For the main temple (Kalan) the level of morphological complexity led to a multi-resolution approach in order to survey the whole structure, the different bricks carvings and the sculpted decorations. In addition the terrain morphology and the presence of vegetation was carefully taken into account. The sum of these factors led to begin from the architectonical survey instead of DTM, in order to minimize the generation of possible aligning errors due to the sliding effect of a huge number of scans required to fill the great number of shadows of the DTM area. For this reason the first central block of the area was represented by the Kalan, in which the closed and strongly 3D geometrical shape was essential to define a point cloud alignment with an acceptable accuracy level. In addition a sequence of DTM point clouds, aligned in the same reference system of the Kalan, was acquired, generating a first DTM reference area. Afterwards the remaining part of the DTM was scanned and aligned to the Kalan range maps. In the same time the $3 \mathrm{D}$ acquisition campaign of the other different monuments was carried out, aligning and creating self-consistent point clouds models. Finally those data were aligned in a common reference system using the DTM raw representations of the buildings.

\subsection{B. 3D laser scanning}

The survey of $\mathrm{G}$ Area regarded both the $3 \mathrm{D}$ geometrical acquisition of five different architectures with associated findings and the 2D image acquisition for texture and environment documentation.

In this phase a dedicated 3D acquisition of the upper part of the Kalan was carried out, in order to scan all the hidden area of this complex geometry. The scanner was positioned at 7 meters from ground in the four corners of the iron structure covering the Temple, acquiring 4 high resolution scans of the whole architecture and the surrounding DTM area. Than a long sequence of architectonic acquisitions was realized around the building and integrated with a detailed one devoted to survey the decorated basement. To avoid the shadow effects generated from the basement, an additional sequence of 3 meters height scans was carried out. Locating the laser scanner in the needed position around the main temple (i.e. the taller ruin of the group) was a crucial point for avoiding lacks in the final survey. Such activity was made possible thanks to the small size and low weight of the chosen instrument, together with the prompt and proactive collaboration of the local personnel involved in the site maintenance, that provided to cobble together structures apparently unsafe but actually very solid and functional to the purpose. In this way nearly any needed capturing position in the 3D space around the building was properly reached.

The second step consisted of the DTM acquisition for creating a geometrical framework in order to locate the whole architectures in a common reference system. For this reason a wider surface respect to the archaeological area was considered, in order to acquire part of the morphological terrain context. During Kalan and DTM acquisition a raw alignment phase was also pursued, in order to verify the presence of lacks in the 3D survey. Thanks to this step, an integrative campaign was planned at the end of the first acquisition stage, scanning all the incomplete areas. The other architectural buildings presented a simpler geometry or fewer decorative portion than the Kalan example, for this reason a simpler acquisition process was adopted, using only the medium resolution set-up, integrated by some special scans for better covering the worst preserved portions.

The last phase focused on the 3D acquisition of some archaeological artifacts that were found during the excavation of the $\mathrm{G}$ area and were then classified inside the store-room of the local museum. This step was planned both to store digitally these important sources and to create $3 \mathrm{D}$ models of decorations that could be re-positioned afterwards on the virtual architectures. For this task a precise survey set was defined, in order to optimize the geometrical resolution coherently with the formal complexity of the sculpted finds.

The photographic campaign was devoted to the acquisition of:

i) architectonic images for texturing projection purposes;

ii) detailed images for the creation of seamless material pictures;

iii) panoramic images to gather a believable representation of the surrounding environment through the stitching of multiple fish-eye photographies; 
iv) few image sets taken around four monuments for experimenting automatic image matching techniques.

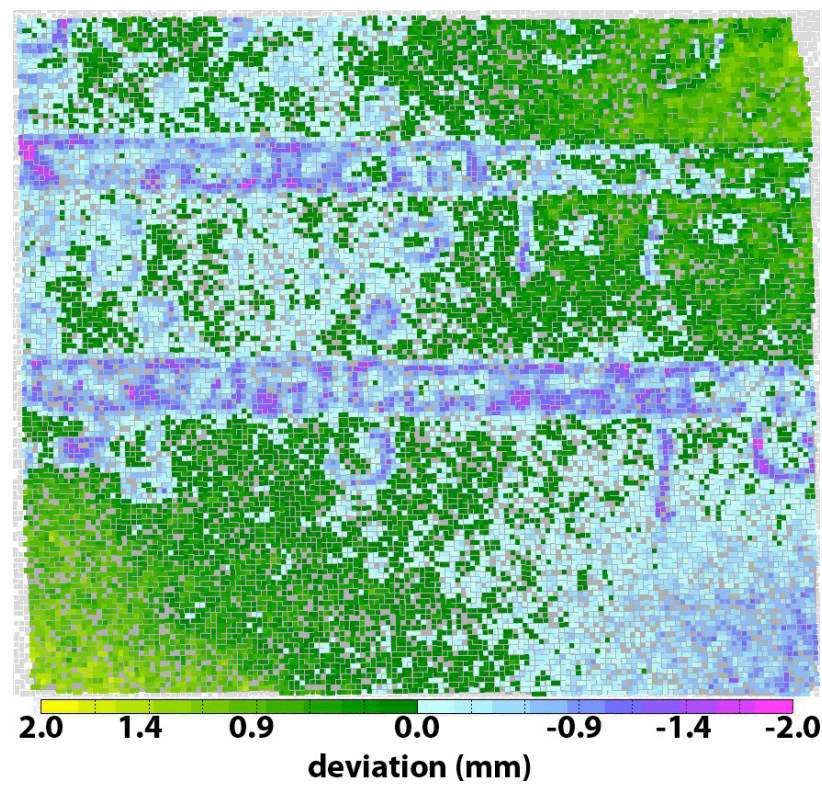

Figure 1. High-resolution point cloud obtained from a Hindu inscription carved on the foundation stone

The main difficulty with these latter images were related to the presence of architectural elements inside dense vegetation, slightly moving due to wind, that involved the presence of images difficult to match each other, with dense image matching results not always good.

However, in a few cases the results of the tests gave very good results, as for example for the 3D capture of the G5 temple. The example was chosen for the presence of a Sanskrit inscription on the foundation stone whose carving depth is in the order of a few millimeters. While the laser scanner measurement uncertainty in the order of 2 to 4 millimeters (depending on the scanned material) made impossible the readability of such tiny geometric detail, an appropriate dense matching processing produced a very accurate detection on carved inscriptions.

The result here was generated by processing 24 images 21 megapixels each, taken with a $20 \mathrm{~mm}$ lens and the camera at about 3 meters from the artifact, with the open source software developed by Institut Géographique National (IGN) in Paris, with the "Apero" module for orienting the shots (PierrotDeseilligny, 2011), and the "Micmac" module for generating the colored cloud of points. The result was then made metric evaluating a scale factor respect to the laser scanning of the same structure.

\subsection{Digital Data Management}

A database structure was created to store this huge amount of 2D and 3D images adding some useful information like date, size and scanner set-up. This allowed to easily managing such information even if not processed immediately. The database was integrated with the reference plan, where all the scanner positions were annotated during the survey. These supports allowed to careful plan and manage the whole 3D scanning campaign, avoiding the post-processing of excessive amounts of data that a device capable to generate 1 million of Points/sec might easily produce.

\begin{tabular}{|l|c|c|c|c|}
\hline & Coarse & Mid & High & Pts x 10 $^{\mathbf{6}}$ \\
\hline G1 (Kalan) & 7 & 43 & 22 & 126 \\
\hline G2 (Gopura) & $/$ & 9 & $/$ & 21 \\
\hline G3 (Mandapa) & $/$ & 8 & $/$ & 15 \\
\hline G4 (Kosagrha) & $/$ & 13 & $/$ & 31 \\
\hline G5 (Pośa) & $/$ & 6 & 4 & 4 \\
\hline DTM & 49 & $/$ & $/$ & 27 \\
\hline 21 Finds & $/$ & $/$ & 60 & 2 \\
\hline Total & 56 & 79 & 86 & 226 \\
\hline
\end{tabular}

Table 2. Point clouds acquired at different resolution levels

\section{REALITY-BASED MODELING}

Every cleaned scan was aligned by means of the ICP algorithm implemented in the Leica Cyclone 3D processing software, in order to position the point clouds of each building in the same reference system. The resulting point clouds were then decimated at $1 \mathrm{~cm}$ sampling step, leveling all the over-sampled portion of the architecture and lowering the amount of 3D data. Each point cloud was subdivided in sub-units whose size was limited to 3 million of points in order to make easier and more controllable the following meshing step.

Every sub-scan was then meshed uniformly. However the resulting high-resolution polygonal models presented both several topological errors, due to residual errors survived to the cleaning phase, and a huge numbers of holes, related to the shadows effects of the complex geometry. These conditions have been critical in particular with not well-preserved buildings; in that case a rather long post-processing phase was faced to generate a watertight polygonal model.

This stage allowed to build the $1 \mathrm{~cm}$ resolution geometry of all the five buildings in the G Area, a $10 \mathrm{~cm}$ resolution DTM of the hill where $G$ Area is located, a set of polygonal models of sculpted finds with a geometrical resolution of $2 \mathrm{~mm}$.

At the end different approaches were followed to texturize such reality based models. For the worst cases of conservation, like $\mathrm{G} 2$ and $\mathrm{G} 4$, a seamless shading pattern originated from real images was chosen as the most practical way.

For the Kalan temple and for the well-preserved architecture most of the texturing was done with the actual images of the ruins projected on the model with the integration of seamless shading patterns for the less characterized components.

The approach followed for acquisition and modeling of the sculpted findings was similar, with a change in terms of geometrical resolution. The models obtained from this process were reconstructed using both a mesh directly generated from the acquired $3 \mathrm{D}$ data, or manually drawing $\mathrm{CAD}$ models for reconstructing polygonal shapes close to the original data. In this step the archeologist's feedback was necessary to suggest the virtual reconstruction of some lacking parts, that was hypothesized coherently with the iconographical sources.

\section{RECONSTRUCTIVE MODELING}

In general the starting information that are needed for a reconstruction modeling process of an archeological ruin are related to geometrical and iconographical data (De Lajonquère, 1902-1912; Parmentier, 1909; Parmentier and Finot, 1904), geographical setting, archaeological and historical remains knowledge. 
From the geometrical point of view, a polygonal model or a simple aligned point cloud can be equally used as reference for the reconstruction process, extracting sequences of sections in $\mathrm{XYZ}$ directions that can be used as wireframe reference box for the definition of the principal lines and surfaces of the reconstructive model.

The polygonal model is used when one of the main goal of a survey project, as the My Son one, is represented by the definition of accurate reality-based models. The creation of a polygonal model is a an articulated and time-consuming process, that imply a semantic division of the entire point cloud, a long process of points artifacts cleaning, the construction of partial decimated polygonal models, a very time consuming filling-holes procedure till the final re-composition of the whole complete model. This articulated process allows reaching a higher accuracy results respect to that obtained through a topography or photogrammetric approach.

The section extraction procedure is very fast and simple, based on intersections between the polygonal surface and a sequence of parallel planes on XYZ direction. In addition the generated broken lines are very usable and manageable inside a $3 \mathrm{D}$ modeling ambient.

On the contrary, a survey project focused only on the reconstruction of architectures can afford only on point clouds, from which a sequence of dense point sections can be extracted. The definition of a section from a point cloud requires at the beginning the construction of two parallel planes positioned at an assigned distance, than the definition of a relative thick points section and finally the projection of this ones on a middle plane, creating a $2 \mathrm{D}$ data source.

In both situation described above, the density of the starting point cloud have to be both coherent with the geometrical characteristics of the real artifact, to avoid lack in geometry, and possibly complete, avoiding the presence of data gaps in the relative sections

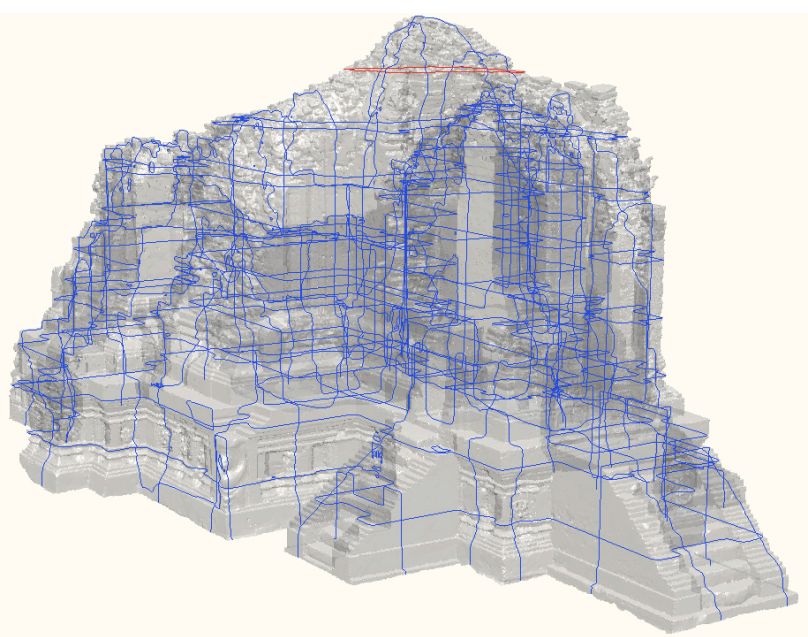

Figure 2. Extraction of horizontal and vertical sections from the mesh model of the Kalan ruin

Beside geometrical data, essential information for the reconstruction process is represented both by historical descriptions and iconographical sources. The former are related to constructive report, architectural ratio description linked to an historical period or general summary of the building phases. But the real and first relation between geometrical and historical sources is due to the drawn plans related to different historical period and the horizontal section of the ruin ( $x-y$ plane) extracted from the data source described above.
Unfortunately this kind of ichnographical sources often lack in objectivity and mutual coherence, due in part for the representation style and the graphical instruments used to create the drawings, in part for the presence of survey errors and low precision in the relative restitution, in part for unsuited data preservation that lead to a modification of the original sources. This lack requests a complex step of "translation" and "mediation" between the rough graphic output of the traditional representation technique and the precise geometries reconstruction, maintaining a proportional coherence between the single pars and the whole. The presence of non-coherent variation in size and proportion between drawings of different historical period can be avoided by digitally stretching the traditional representations with the real dimensions coming from the survey.

In this case different sections extracted from the reality-based model were used to rescale the iconographical sources, verifying their correct representation. This normalization process started first from the plans, secondary to sections and prospects that were modified, in order to reach a sequence of $2 \mathrm{D}$ coherent representations, acceptable from the geometrical and historical point of view.

Despite this normalization process, a disproportion between plans, sections and facades can persist, for this some considerations on architectural syntax have to be added, relative both to historical or formal elements and to a general evaluation on buildings use at time, due to rituality and behavior of the local people. In our case, the role of each building was considered in particular for refining the Kalan height estimation. At Cham time and during the religious ceremony, the young monks accompanying the Brahmin in his journey to God (that for the Hindu religion is inside the Kalan) entered into the Mandapa and stopped there, leaving the Brahmin alone to enter into the holy enclosure from the Gopura (i.e. the portal). For this reason the Gopura entrance door surely prevented to see the holiest building, i.e. the Kalan. This consideration allowed defining a believable dimensional range for Kalan temple, between 15 and 20 meters, identifying 8 meters as suitable hypothesis for the Gopura height.

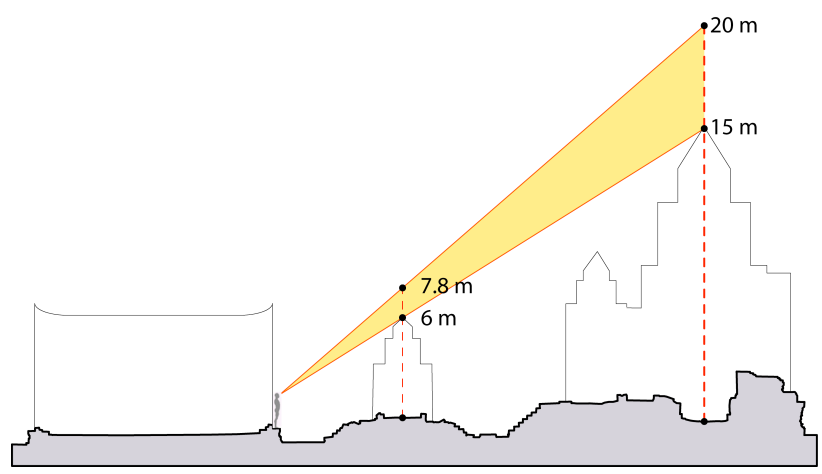

Figure 3. Height analysis based on religious considerations according with a monk of the group accompanying the Brahmin should have remained in the assembly hall and from that point of view the portal should have hid the main temple.

At this step three different versions of the most complex building - the Kalan Temple - were created, working in particular on the ratio between the different levels of the architecture. These raw outputs allowed visualizing for the first time the $3 \mathrm{D}$ virtual reconstruction, evaluating with the archaeologists pros and cons of the different solutions.

In the second step every building was refined, carving the virtual walls with hypothetical pilasters and niches. 
The introduction of these elements was quite complex for the very little information coming from the ruins, but some Parmentier's drawings were integrated with different photographs of similar temples still preserved in other archeological areas.

The comparison with other similar stylistic elements was essential at this stage, in order to identify common structural patterns, which have been afterwards adapted to the $G$ buildings.

The addition of such architectonical elements allows reaching a higher refined model, defining the structural skeleton of the temple and preparing the architectonical part devoted to decorative elements. Also in this delicate passage the archeologist's participation was essential to validate the solution adopted.

In the last modeling step the latest architectonic refinements all the surveyed sculpted decorations, discovered near the buildings and digitized in the store-room, were located in the supposed right places. Evaluating these little metrical references inside the virtual structure represents a crucial verification of the whole reconstruction process. In this step the archeology validation concerns with different steps. Initially the correct position of the sculptures and the dimensional relation between decorations and architecture structure has to be confirmed. When these two conditions are verified, the process can proceed to the final texturizing step. If not, different levels of model variations have to be considered. The process of sculptures repositioning must proceed until a good solution is reached. The new decorative set-up has to consider also the relation with the architectonical structure, which must be rearranged to be coherent with the decorative references.

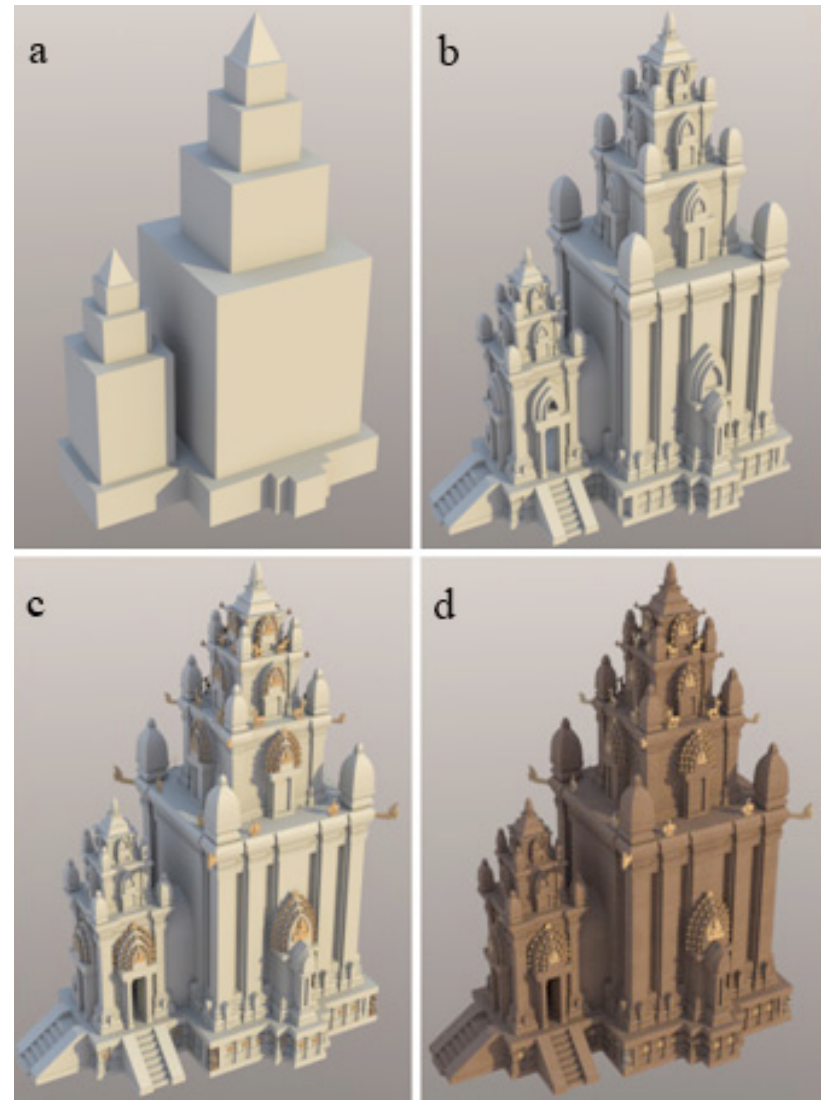

Figure 4. Reconstructive sequence: a) volumetric model; b) architectural structure; c) architecture with decorations; d) final texturized model
In the better condition, a simple reshaping of secondary building portion can allow to maintain the modification level inside the decoration step. Instead, evident modifications of the structures require going back to the structure level of definition, in which a new solution will be suggested. At the end, if these last alterations condition the ratio of the whole architecture, the principal dimensions of the raw models has to be re-considered. In our case only some modifications in niches proportions were applied. In this phase the modeling level led to such an advanced level of detail that even the experts demonstrated doubts and decided not to introduce unknown elements inside the architecture, leaving intentionally some informative lacks on the reconstructive models.

In the final step the different texture mapped architectural models, including all their decorations, were merged in a single three-dimensional virtual reproduction of the G group.

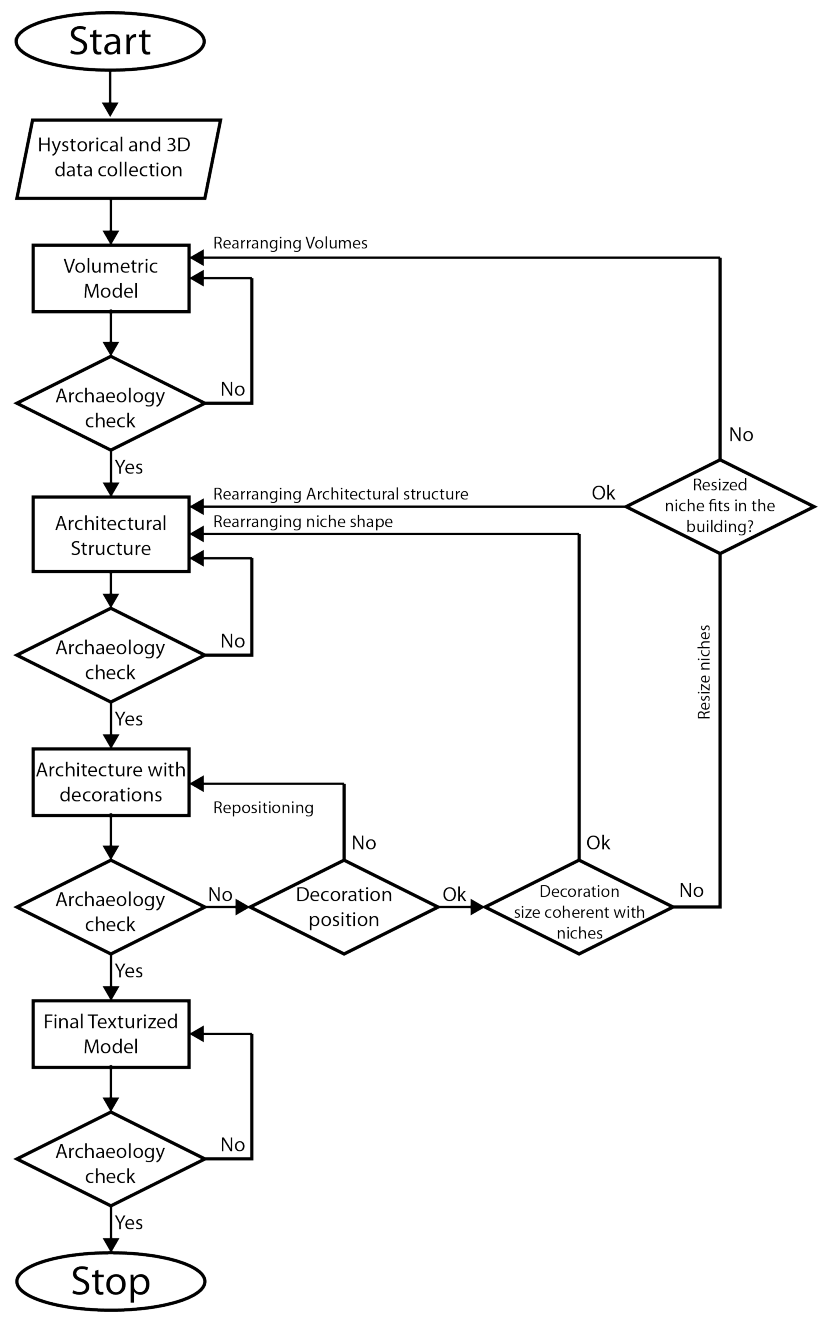

Figure 5. Flow diagram describing the reconstruction process based on the interaction between historical sources and 3D data

\section{CONCLUSIONS}

This paper describes a process of acquisition and modeling applied to create a virtual reconstruction of lost architectures located in a striking context, the Mỹ Sơn archaeological area in Vietnam. Inside a common used 3D acquisition and modeling approach some different topics are discussed, suggesting both optimized procedures for data processing and communication. In particular an iterative methodology is suggested to support 
the interpretative modeling step, simplifying the feedback on virtual models by the archeologists. This solution gives a significant improvement on the complex procedure of 3D reconstruction modeling, supplying both an instrument of communication and valorization of the cultural heritage site helping the interpretation of archaeological and architectural ruins. As future development it would be interesting to explore an enhanced communication level between the different historical and technological experts, based on social networking instruments, and annotations on renderings or directly on $3 \mathrm{D}$ models.

\section{REFERENCES}

Bernard Frischer and Anastasia Dakouri-Hild, eds. "Beyond Illustration: 2D and 3D Digital Technologies, as Tools for Discovery in Archaeology", BAR International Series 1805, Oxford: Archaeopress, 2008.

Ky Phuong, T., Rejniewicz, L., Drygallo, R. , Kwiatkowski, K. Récherches sur les Monuments du Champa, Interim Report de la Mission polono-vietnamienne, Eds. PKZ, vol. 1, Varsovie, 1990.

Coedes, G., The Indianized States of Southeast Asia, in Proceedings on the 1968 Status of the Latest Research on the Absorption Of Champa by Viet Nam, Po Darma, 1988.

Hardy, A., Cucarzi M., Zolese, P. Champa and the Archaeology of Mỹ Sơn (Vietnam), NUS Press, Singapore, 2009.

Levoy, M., Pulli, K., Curless, B., Rusinkiewicz, S., Koller, D., Pereira L., et al. The Digital Michelangelo Project: 3D scanning of large statues, in Proceedings of ACM SIGGRAPH, 2000, pp. 131-144.

Bernardini F., Rushmeier, H. The 3D Model Acquisition Pipeline, Computer Graphics Forum, vol. 21, no. 2, pp. 149172, Jun. 2002.

Beraldin, J-A., Picard, M., El-Hakim, S.F., Godin, G., Valzano, V., Bandiera A. et al. Virtualizing a Byzantine Crypt by Combining High-resolution Textures with Laser Scanner 3D Data. In Proceedings of VSMM2002, Gyeongju, Korea, 2002, pp. 3-14.

Guidi, G., Russo M., Beraldin, J-A. Acquisizione e modellazione poligonale, McGraw Hill, 2010.

El-Hakim, S., Beraldin, J-A., Picard M., Cournoyer, L. Surface Reconstruction of Large Complex Structures from Mixed Range Data - The Erechtheion Experience, in Proceedings of XXI Congress of the International Society for Photogrammetry and Remote Sensing (ISPRS), vol. 37, Beijing, China, 2008, pp. 1077-1082.

Guidi, G., Remondino, F., Russo, M., Menna, F., Rizzi A., Ercoli, S. A multi-resolution methodology for the 3D modeling of large and complex archeological areas, in Special Issue in International Journal of Architectural Computing (IJAC), 2009, pp 39-55.

Remondino, F. Heritage Recording and 3D Modeling with Photogrammetry and 3D Scanning". Remote Sensing, 3(6), 2011, pp. 1104-1138.

Frischer, B., Niccolucci, F., Ryan N., Barceló, J. A. From CVR to CVRO: the Past, Present and Future of Cultural Virtual
Reality, in Proceedings of the VAST EuroConference, Arezzo, Italy, 2002, pp. 1-12.

VV. AA., Beyond Illustration: 2D and 3D Digital Technologies as Tools for Discovery in Archaeology, Bernard Frischer and Anastasia Dakouri-Hild eds., Archaeopress, Oxford, 2008.

Rua, H., Alvito, P. Living the past: 3D models, virtual reality and game engines as tools for supporting archaeology and the reconstruction of cultural heritage - the case-study of the Roman villa of Casal de Freiria, Journal of Archaeological Science, vol. 38, no. 12, 2011, pp. 3296-3308.

El-Hakim, S., Lapointe J., Whiting, E. Digital Reconstruction and 4D Presentation through Time, in Proceedings of the International Conference on Computer Graphics and Interactive Techniques (SIGGRAPH), Los Angeles, California, 2008.

Russo M., Guidi, G., Reality-based and reconstructive models: digital media for cultural heritage valorization, in SCIentific RESearch and Information Technology (SCIRES-IT), vol. 2 (4), CASPUR-CIBER Publishing, 2011.

De Lajonquère, E. L., Inventaire archéologique de l'Indochine, vol. 3, Paris, 1902-1912.

Parmentier, H., Inventaire descriptif des Monuments Cams de l'Annam", tome II, Imprimerie Nationale, Paris, 1909.

Parmentier, H., Finot, L. Le cirque de Mi-son (Quang-nam): les monuments par Henri Parmentier, les inscriptions par Louis Finot", resumè from Bulletin de l'Ecole française d'ExtrêmeOrient, F.-H. Schneider, Hanoi, 1904.

Pierrot-Deseilligny, M., Cléry. I. APERO, an Open Source Bundle Adjustment Software for Automatic Calibration and Orientation of a Set of Images. Proceedings of the ISPRS Commission V Symposium, Image Engineering and Vision Metrology, Trento, Italy, 2-4 March 2011.

\section{ACKNOWLEDGMENTS}

The authors would like to thank Patrizia Zolese, the archeologist expert in Cham architecture that produced most of the archaeological suggestions for the final model, the Centre for the Conservation and Valorization of Cultural Heritage of Politecnico di Milano (CCVBC) through Maurizio Boriani and Fulvia Premoli for the general project management, Mauro Cucarzi, President of Lerici Foundation, for the organization of the operations on the field and the availability demonstrated in all stages of the project, Le Thanh Vinh from ICM-Hanoi Institute as local scientific counterpart and Livio De Luca, from CNRS - MAP (Fance), for the photogrammetric automatic image orientation and dense point cloud generation with Apero and MicMac respectively.

The contribution of Dang Khanh Ngoc, Mara Landoni and Michele Romano for the useful support in situ and precious indications supplied for the interpretation of the ancient Cham architectures has also to be gratefully acknowledged.

A last special thank is due to all the local Vietnamese personnel in Mỹ Sơn, who have contributed, with their operating ability, to create the optimal condition for surveying the $\mathrm{G}$ area. 